\title{
Eight-year trends in food, energy and macronutrient intake in a sample of elderly German subjects
}

\author{
Svenja M. Jungjohann ${ }^{1}$, Petra M. Lührmann ${ }^{1}$, Ralf Bender ${ }^{2}$, Maria Blettner ${ }^{2}$ \\ and Monika Neuhäuser-Berthold ${ }^{1} *$ \\ ${ }^{1}$ Institute of Nutritional Science, Justus-Liebig-University, Goethestr. 55, D-35 390 Giessen, Germany \\ ${ }^{2}$ Department of Medical Biometry, Epidemiology \& Informatics, Johannes Gutenberg-University, Mainz, Germany
}

(Received 26 May 2004 - Revised 2 September 2004 - Accepted 18 October 2004)

\begin{abstract}
Time trends in the food and the corresponding energy and macronutrient intake between 1994 and 2002 are investigated as part of the longitudinal study on nutrition and health status in an ageing population in Giessen, Germany (GISELA study). The dietary intake is assessed via a $3 \mathrm{~d}$ estimated dietary record especially developed and validated for this study. A total of 2135 records from 532 subjects, aged 60 years and over, are analysed separately according to sex and age groups (born 1904-1928 and born 1929-1942). Results show that the food, energy and macronutrient intake of the GISELA subjects stayed fairly stable over the study period. However, some significant changes in the consumption pattern are observed, predominantly in the women and the younger age groups, which correspond to the national trends in Germany. Most obvious changes observed among the GISELA subjects are the increased intake of water (between +21.05 and $+41.61 \mathrm{ml} / \mathrm{d}$ per year) and vegetables (between +2.94 and $+3.38 \mathrm{~g} / \mathrm{d}$ per year) and a reduced consumption of coffee and tea (between -10.65 and $-15.99 \mathrm{ml} / \mathrm{d}$ per year) as well as of meat (between -1.79 and $-2.56 \mathrm{~g} / \mathrm{d}$ per year). The healthier food choices and the ability to change food habits could be related to the relatively high health-awareness of the GISELA subjects compared to the federal average of equivalent age groups.
\end{abstract}

Elderly: Food, energy and macronutrient intake: Estimated dietary record: Time trends

Since the beginning of the 19th century in Germany and other western countries the proportion of elderly people in the population has continuously increased (Kinsella, 1992; World Health Organization, 2002). Due to these demographic changes there is an increasing need for information concerning the relation between nutrition and the health status of older age groups.

Optimum dietary intake is fundamental to ensure the health and life quality of older people. It also has economic relevance, because it influences the capability of older people to continue to live independently in their communities, which reduces the costs of public health systems and relieves the burden on national budgets particularly in western societies (Horwath, 1989; World Health Organization, 1990). Primary data on dietary intake and changes in food consumption in the elderly are required in order to assess the relation between nutrition and the health status of older age groups and to determine dietary objectives as well as to establish dietary guidelines and develop related recommendations.

During the last two decades several nutrition surveys have been conducted covering free-living as well as institutionalised elderly people. Most of these were carried out as cross-sectional studies (de Almeida et al. 2001; Mensink, 2002). Cross-sectional surveys, however, have limited explanatory power when it comes to analysing trends, in this case of the ageing process under the influence of various factors. Longitudinal surveys, which collect data by repeatedly assessing the same individuals, have a lower error vari ance than the data of cross-sectional surveys. More accurate conclusions on age and time effects can be drawn from longitudinal surveys, because they make it possible to assess changes in individual subjects, cohort-specific and secular trends, and other influencing factors.

Data concerning possible long-term changes in dietary habits in free-living or non-institutionalised elderly people are still lacking. The SENECA study and the WHO MONICA project are two of the few surveys that have applied a longitudinal approach in order to benefit from the above-mentioned positive attributes of repeated long-term data assessments. The SENECA study was brought into being with the objective to examine the dietary patterns of elderly men and women and their relationship to various indicators of health. Assessments took place in several towns all over Europe, but no data were gathered in Germany (SchlettweinGsell \& Barclay, 1996). The WHO MONICA project, which was carried out with the aim of investigating the relationship between changes in diet and cardiovascular diseases, involved German subjects, however, the sample covered 25-64-year-old subjects and thereby only included a minor group of elderly people (Schaeffler et al. 1996).

In 1994, a longitudinal study on older adults above the age of 60 years was initiated with the aim of investigating the nutritional and health status of an ageing population in Giessen, Germany (GISELA study). The GISELA study, which is the first prospective cohort study on nutrition and health status of elderly 
people in Germany, is expected to continue over a longer period of time. This survey documents developments during the ageing process as well as various influencing factors and analyses their interactions. Within the scope of this study the food intake and corresponding energy and nutrient intake of the elderly subjects are assessed via a $3 \mathrm{~d}$ estimated dietary record. The objectives of the investigation covered by this paper are to outline trends in the food and energy, as well as macronutrient, intake of the GISELA subjects between 1994 and 2002.

\section{Subjects and methods}

\section{Subjects}

Subjects were participants of the GISELA study. The GISELA study is a prospective cohort study in which the nutritional and health status of free-living elderly citizens in Giessen have been observed at annual intervals since 1994 and at biannual intervals since 1998, respectively. Within the scope of this study food intake and corresponding energy and nutrient intake as well as anthropometric data, body composition, energy expenditure and various biochemical parameters in blood of the study participants are examined. All investigations take place in the Institute of Nutritional Science in Giessen, Germany between June and November between 6.00 and 10.00 hours after an overnight fast.

Study participants had to be at least 60 years of age, physically mobile and available around Giessen on a long-term basis. In 1994 and 1995, 220 and 107 subjects, respectively, were recruited by physicians, notices, senior citizens' meetings, advertisements in local newspapers as well as by recruitment through subjects who had already been participating. Since 1996, in each follow-up cohorts of about forty to sixty subjects have been recruited for the study by the participants themselves. Between 1994 and 2002 a total of 2135 records from 532 subjects (373 women and 159 men) were evaluated. Because sex and age influence food intake, the analyses of data were carried out separately for women and men as well as for subjects born in or before 1928 and born after 1928. Table 1 shows the number of records evaluated from 1994 to 2002 according to sex and age groups. Between one (102 subjects) and seven (91 subjects) records per study participant were available. On average four records were evaluated per participant.

The age of the male and female subjects covered by the study group ranged from 60 to 91 years. Most of the participants had an intermediate school qualification (females $86.0 \%$; males $66.9 \%$ ) and only a few subjects had no school qualification (females $0.6 \%$; males $1.3 \%$ ). Of the females $13.4 \%$ and of the males $31.8 \%$ had a university entrance qualification.

Of the women $70.2 \%$ and $25.2 \%$ of the men had never smoked. In their first year of participation only $8.2 \%$ of the women and $13.5 \%$ of the men were smokers; $21.6 \%$ of the women and $61.3 \%$ of the men had formerly smoked, but had by then quit smoking.

\section{Food, energy and macronutrient intake}

To determine food intake, a $3 \mathrm{~d}$ estimated dietary record was especially developed for the GISELA study. The dietary record consists of 146 food items, subdivided into sixteen food groups. For every food item both typical household measures (e.g. slice, cup, spoon) and the appropriate weights were given. So with this information the subjects were supposed to estimate the 
amount of their food consumption. Furthermore, the participants had the possibility to write down any consumed food they were unable to classify under the heading 'others'. The subjects were instructed to protocol their entire food intake in the dietary record on three consecutive days directly after consumption, starting on a Sunday. The validity of the dietary record was evaluated by means of nitrogen excretion in the $24 \mathrm{~h}$ urine, and by comparing energy intake and resting metabolic rate determined by indirect calorimetry according to Goldberg et al. (1991). Significant differences were found neither in women nor in men between calculated nitrogen intake (13.4 (SD 2.2) and 15.0 (SD 2.0) g, respectively) and nitrogen excretion (12.9 (SD 2.1) and 15.7 (SD 3.0) g, respectively). The ratio between reported energy intake and basal metabolic rate was 1.62 (SD 0.46) in women and 1.53 (SD $0.46)$ in men. Results have proved the dietary record as suitable to determine energy and nutrient supply of the elderly. Development and validation of the dietary record are described in detail elsewhere (Lührmann et al. 1999).

To analyse the $3 \mathrm{~d}$ dietary record first, the foods recorded under the heading 'others' were classified among given food items according to their energy and nutrient intake. Then energy and nutrient contents of the food items were calculated by means of the German Food Code and Nutrient Data Base version II.3 (Bundesinstitut für gesundheitlichen Verbraucherschutz und Veterinärmedizin, Berlin, Germany; Dehne et al. 1999) using the nutrient calculation program DGE-PC professional (Deutsche Gesellschaft für Ernährung e.V., Frankfurt/Main, Germany). Food, energy and nutrient intakes were calculated as individual mean values of the three recorded days. Total food intake was defined as the sum of all recorded foods and beverages. The difference between total food intake and beverage intake was named as solid food. The beverage group 'juice' refers to fruit juices made from $100 \%$ fruit, whereas the beverage group 'soft drinks' implies carbonated drinks and others. The food item 'sweets' includes sugar, pudding, chocolate and assorted candies. The food item 'gravies and soups' includes gravies and soups, but also dressings and sauces.

\section{Anthropometric data}

Body weight was measured with a calibrated digital scale (Seca, Vogel \& Halke, Hamburg, Germany) to the nearest $0.1 \mathrm{~kg}$ after shoes, coats and sweaters had been removed. Depending on the estimated weight of the remaining clothes $0.5-1.0 \mathrm{~kg}$ was subtracted from the measured weight. Body height was determined by a height measurement device integrated in the scale without shoes to the nearest $0.005 \mathrm{~m}$. Body height was measured with back and heels against the upright bar of the height scale, looking straight ahead, and standing erect with some assistance when necessary.

\section{Non-dietary data}

Non-dietary data, such as age, education level and smoking habits, were obtained from the subjects by questionnaire.

\section{Statistical analyses}

To analyse the influence of time (trend) on the variables studied, linear mixed models were used with subject as random effect. In contrast to conventionally used linear models for repeated measurements, mixed models do not require all subjects to have the same number of measurements. Therefore, instead of eliminating subjects with missing data it was possible to use all available data (Littell et al. 1998). For parameter estimation the maximum likelihood method was used with unstructured covariance matrices. Because food intake varies with sex and age, different age and sex groups were analysed separately. In these models, besides the random subject effect, time was analysed as a fixed effect. In Tables 2-7 results are presented as intercept of regression model (expected value for time $=1994$ considering all available data), standard error (SE), time trend per year (regression coefficient $\beta$; increase: + , decrease: - ) and $P$ value. To investigate whether significant differences in time trends between age and sex groups exist, additional mixed models were carried out for the total sample. In these models, besides the random subject effect, time, sex and age group were analysed as fixed effects. Differences in time trends between age and sex groups were expressed as interaction terms between time and sex and age group. If any significant interaction terms were found, the corresponding $P$ values are given as footnotes in Tables $2-7$. Results are considered statistically significant when $P$ values are less than 0-05. For computations SAS PROC MIXED (SAS version 8.02, SAS Institute, Cary, NC, USA) was used.

\section{Ethical considerations}

The GISELA study is observational, non-intervening and non-invasive. The study protocol was approved by the Ethical Committee of the Faculty of Medicine at the Justus-Liebig-University Giessen, Germany, and a written informed consent was obtained from each study participant.

Table 2. Anthropometric data of the GISELA subjects 1994-2002

\begin{tabular}{|c|c|c|c|c|c|c|c|c|c|}
\hline & & Intercept & $\mathrm{SE}$ & $\beta$ & $P$ & Intercept & $\mathrm{SE}$ & $\beta$ & $P$ \\
\hline & Men & $172 \cdot 8$ & 0.6 & -0.08 & $<0.0001$ & 173.0 & 0.7 & -0.03 & 0.0698 \\
\hline \multirow[t]{2}{*}{ Body weight $(\mathrm{kg})^{\mathrm{c}}$} & Women & 66.4 & 0.7 & -0.01 & 0.8635 & 71.4 & 0.9 & 0.25 & $<0.0001$ \\
\hline & Men & $79 \cdot 6$ & $1 \cdot 2$ & 0.00 & 0.9919 & $80 \cdot 0$ & $1 \cdot 2$ & 0.20 & 0.0045 \\
\hline
\end{tabular}

$\beta$, time trend per year.

${ }^{\mathrm{a}-\mathrm{d}}$ Trend analyses in total sample show: ${ }^{\mathrm{a}}$ significant difference in trend results between women and men: $P=0.0082$; ${ }^{\mathrm{b}}$ significant difference in trend results between age groups: $P<0.0001$; ' significant difference in trend results between age groups: $P=0.0004$; ${ }^{d}$ significant difference in trend results between age groups: $P=0.0064$. 
Table 3. Food intake ( $\mathrm{g} / \mathrm{d}$ ) of the GISELA subjects 1994-2002

\begin{tabular}{|c|c|c|c|c|c|c|c|c|c|}
\hline & & Intercept & SE & $\beta$ & $P$ & Intercept & SE & $\beta$ & $P$ \\
\hline Total food intake & Men & $3021 \cdot 7$ & $73 \cdot 6$ & $8 \cdot 84$ & 0.3948 & $2769 \cdot 6$ & $95 \cdot 7$ & $39 \cdot 32$ & 0.0012 \\
\hline \multirow[t]{2}{*}{ Solid food intake } & Women & $1420 \cdot 8$ & $28 \cdot 4$ & 9.51 & 0.0539 & $1362 \cdot 6$ & $29 \cdot 7$ & -0.44 & 0.8986 \\
\hline & Men & 1721.9 & $54 \cdot 4$ & $2 \cdot 50$ & 0.7642 & $1592 \cdot 8$ & $53 \cdot 8$ & $4 \cdot 84$ & 0.4964 \\
\hline Beverage intake & Men & $1261 \cdot 0$ & $55 \cdot 1$ & 8.92 & 0.2253 & $1170 \cdot 6$ & $75 \cdot 3$ & 33.02 & 0.0003 \\
\hline
\end{tabular}

$\beta$, trend results per year.

\section{Results}

\section{Subjects}

Table 2 presents the anthropometric data of the GISELA subjects. A significant decline in the height of the subjects is noticeable in the women of both age groups and in the older men. Significant differences in the time trends are found between age and sex groups. A higher decrease of the body height is observed in the older age groups and in women. With regard to body weight and BMI trends differ significantly between the age groups. The younger groups show an increase in body weight over the years, whereas no significant changes are observed in the older groups. The BMI shows a significant increase among women and younger men. In older women only a slight increase is observed and in older men BMI remains constant.

\section{Trends in food intake}

Between the years 1994 and 2002 a significant increase in the total food intake is observed in the women of both age groups and in the younger men (Table 3 ). This increase is caused by the higher intake of beverages, which shows the same significant trends for women and the younger men. The total food and beverage intake of the older men shows no changes. The intake of solid food reveals no changes over the years in all groups.

Table 4 presents trends in the intake of beverages. All subjects show a significant increase in the intake of water and-except for the younger men-a significant decrease in the intake of coffee and tea. The intake of juice increased significantly in the younger women, while the intake of soft drinks in the older men reduced significantly. The juice and soft drink intake of the other age and sex groups did not change significantly. With regard to the intake of fruit and herb tea or alcoholic beverages no significant trends are found.

Table 5 shows significant changes in the intake of high-carbohydrate foods. The older men reduced the intake of bread and bakery products as well as the intake of potatoes and potato products. The younger women also reduced the intake of potatoes and potato products and increased the cereal product intake. Furthermore, an increase in potatoes and potato products is observed in the older women. The younger women slightly increased the intake of fats and oils, however they reduced the consumption of gravies and soups over the years. The intake of sweets decreased in younger men. The other age and sex groups show no significant trends in the intake of sweets, fats and oils, as well as gravies and soups.

With regard to the intake of high-protein foods shown in Table 6 , no changes in the intake of meat products and milk and dairy products are observed. The intake of meat among the younger generation of men and women shows a significant decrease. Women increased the consumption of fish significantly and the older women additionally ate more eggs. The intake of meat, fish and eggs of the other age and sex groups did not change significantly.

In all groups the intake of fruits and fruit products did not vary over the years. A significantly higher intake of vegetables is observed in all age and sex groups, except for the older women, who show no significant changes.

Table 4. Beverage intake (ml/d) of the GISELA subjects 1994-2002

\begin{tabular}{|c|c|c|c|c|c|c|c|c|c|}
\hline & & \multicolumn{4}{|c|}{ Subjects born 1904-1928 } & \multicolumn{4}{|c|}{ Subjects born 1929-1942 } \\
\hline & & Intercept & SE & $\beta$ & $P$ & Intercept & SE & $\beta$ & $P$ \\
\hline \multirow[t]{2}{*}{ Water $^{\mathrm{a}}$} & Women & $491 \cdot 3$ & $28 \cdot 4$ & 21.05 & $<0.0001$ & $471 \cdot 7$ & 33.7 & $41 \cdot 61$ & $<0.0001$ \\
\hline & Men & $396 \cdot 2$ & $36 \cdot 8$ & 21.69 & $<0.0001$ & 323.2 & $45 \cdot 2$ & $38 \cdot 16$ & $<0.0001$ \\
\hline \multirow[t]{2}{*}{ Fruit and herb tea } & Women & $191 \cdot 3$ & $19 \cdot 7$ & 4.40 & 0.1752 & $154 \cdot 1$ & $21 \cdot 1$ & $2 \cdot 51$ & 0.3880 \\
\hline & Men & $98 \cdot 8$ & $28 \cdot 5$ & $4 \cdot 79$ & 0.1312 & $134 \cdot 8$ & $26 \cdot 6$ & -0.32 & 0.9367 \\
\hline \multirow[t]{2}{*}{ Juice } & Women & 94.5 & 9.9 & $1 \cdot 72$ & 0.3234 & $81 \cdot 2$ & $10 \cdot 1$ & $4 \cdot 24$ & 0.0125 \\
\hline & Men & $87 \cdot 8$ & $12 \cdot 9$ & -3.92 & 0.1523 & $76 \cdot 9$ & $16 \cdot 0$ & 3.00 & 0.3166 \\
\hline \multirow[t]{2}{*}{ Soft drinks } & Women & $29 \cdot 0$ & $6 \cdot 1$ & $2 \cdot 01$ & 0.1401 & 33.8 & 8.5 & 0.03 & 0.9841 \\
\hline & Men & $69 \cdot 1$ & $11 \cdot 4$ & $-2 \cdot 01$ & 0.0032 & $78 \cdot 2$ & $35 \cdot 0$ & -1.05 & 0.8385 \\
\hline \multirow{2}{*}{ Coffee and tea } & Women & $439 \cdot 4$ & $16 \cdot 5$ & $-10 \cdot 65$ & $<0.0001$ & $512 \cdot 2$ & $19 \cdot 2$ & -15.99 & $<0.0001$ \\
\hline & Men & $504 \cdot 8$ & $31 \cdot 2$ & -11.57 & 0.0054 & $476 \cdot 6$ & $29 \cdot 6$ & -4.97 & 0.1024 \\
\hline \multirow[t]{2}{*}{ Alcoholic beverages } & Women & 67.5 & $7 \cdot 6$ & 0.74 & 0.5012 & 83.5 & 8.9 & -0.90 & 0.3880 \\
\hline & Men & 231.3 & 33.2 & $-3 \cdot 71$ & 0.4600 & $224 \cdot 7$ & $35 \cdot 2$ & -4.02 & 0.2648 \\
\hline
\end{tabular}

$\beta$, trend results per year.

${ }^{a}$ Trend analysis in total sample shows significant difference in trend results between age groups: $P<0.0247$. 
Table 5. Intake of high-carbohydrate foods, fats, oils, gravies and soups (g/d) of the GISELA subjects 1994-2002

\begin{tabular}{|c|c|c|c|c|c|c|c|c|c|}
\hline & & \multicolumn{4}{|c|}{ Subjects born 1904-1928 } & \multicolumn{4}{|c|}{ Subjects born 1929-1942 } \\
\hline & & Intercept & SE & $\beta$ & $P$ & Intercept & SE & $\beta$ & $P$ \\
\hline \multirow[t]{2}{*}{ Bread and bakery products } & Women & $188 \cdot 7$ & 5.5 & -0.79 & 0.4678 & 193.9 & $6 \cdot 0$ & -1.18 & 0.2031 \\
\hline & Men & $260 \cdot 6$ & 11.4 & $-5 \cdot 60$ & 0.0008 & $241 \cdot 1$ & $9 \cdot 3$ & -0.54 & 0.6687 \\
\hline \multirow[t]{2}{*}{ Cereal products } & Women & $52 \cdot 8$ & 3.4 & 1.39 & 0.0571 & $44 \cdot 2$ & $3 \cdot 8$ & $1 \cdot 32$ & 0.0469 \\
\hline & Men & $53 \cdot 5$ & $5 \cdot 7$ & $1 \cdot 13$ & 0.3422 & $41 \cdot 7$ & $7 \cdot 8$ & 1.78 & 0.2097 \\
\hline \multirow[t]{2}{*}{ Potatoes and potato products ${ }^{a}$} & Women & $97 \cdot 7$ & 4.8 & 1.97 & 0.0335 & $105 \cdot 9$ & $5 \cdot 1$ & -1.95 & 0.0231 \\
\hline & Men & $127 \cdot 8$ & $8 \cdot 0$ & -2.06 & 0.0245 & $117 \cdot 0$ & 8.2 & -1.07 & 0.4661 \\
\hline \multirow[t]{2}{*}{ Sweets } & Women & $43 \cdot 7$ & 2.5 & 0.65 & 0.2359 & $40 \cdot 1$ & $2 \cdot 7$ & 0.05 & 0.9100 \\
\hline & Men & $52 \cdot 2$ & $5 \cdot 4$ & -1.44 & 0.1092 & 52.5 & 5.0 & -1.34 & 0.0335 \\
\hline \multirow[t]{2}{*}{ Fats and oils } & Women & $14 \cdot 1$ & 0.7 & 0.12 & 0.2593 & $12 \cdot 3$ & 0.6 & 0.20 & 0.0139 \\
\hline & Men & $16 \cdot 5$ & $1 \cdot 1$ & -0.08 & 0.6672 & 13.7 & $1 \cdot 0$ & -0.03 & 0.7984 \\
\hline \multirow[t]{2}{*}{ Gravies and soups } & Women & $48 \cdot 7$ & 4.6 & 0.45 & 0.6104 & $52 \cdot 1$ & 5.5 & -1.79 & 0.0351 \\
\hline & Men & $60 \cdot 0$ & 7.4 & 0.41 & 0.6871 & 50.5 & $5 \cdot 3$ & 0.42 & 0.4301 \\
\hline
\end{tabular}

$\beta$, trend results per year.

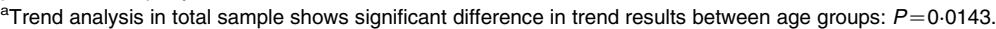

\section{Trends in energy and macronutrient intake}

Table 7 shows that the energy intake stayed stable over the years in all age and sex groups, except in the group of younger men, where a significantly increasing trend is observed.

The macronutrients intake expressed as percentage of energy intake only changed significantly in the group of the younger women and older men. Among the younger women the percentage of carbohydrate intake increased and the percentage of alcohol intake reduced. Among the older men a reduction of the percentage of carbohydrate intake and an increase of the percentage of protein and alcohol intake is observed.

\section{Discussion}

\section{Subjects}

For the interpretation of the results it has to be taken into consideration that the GISELA subjects differ from the average older German citizens. Comparison with the older federal average shows that the subjects of the GISELA study have a higher educational level, are more physically active and have a lower percentage of smokers (Junge \& Nagel, 1999; Mensink, 2002;
Krems et al. 2004). Furthermore, the GISELA men and women of both age groups weigh less and consequently also have a lower BMI than the older federal average (women $29.0 \mathrm{~kg} / \mathrm{m}^{2}$; men $28 \cdot 1 \mathrm{~kg} / \mathrm{m}^{2}$ ) (Mensink, 2002).

Compared to a representative sample of elderly Germans (6579 years) the beverage, fruit and fruit product as well as the bread and bakery product intake of the GISELA subjects is significantly higher, so is the intake of milk and dairy products and fish, especially in the older age groups. The egg and vegetable intake of the GISELA subjects is however, significantly lower than the federal average. The contribution of the macronutrients to the energy intake of the GISELA subjects is similar to the federal average. However, a slightly more positive distribution of the macronutrients is found in the GISELA subjects. The contributions of protein and carbohydrates are marginally higher and the contribution of fat is slightly lower than the federal average, so is the percentage of alcohol of the GISELA men (Mensink, 2002).

These differences from the average older German could be a sign for relatively high health-awareness of the GISELA subjects, probably associated with the voluntary participation in our nutritional study.

Table 6. Intake of high-protein foods, vegetables and fruit $(\mathrm{g} / \mathrm{d})$ of the GISELA subjects $1994-2002$

\begin{tabular}{|c|c|c|c|c|c|c|c|c|c|}
\hline & & \multicolumn{4}{|c|}{ Subjects born 1904-1928 } & \multicolumn{4}{|c|}{ Subjects born 1929-1942 } \\
\hline & & Intercept & SE & $\beta$ & $P$ & Intercept & SE & $\beta$ & $P$ \\
\hline \multirow[t]{2}{*}{ Meat $^{a}$} & Women & $77 \cdot 2$ & $3 \cdot 6$ & 0.55 & 0.3512 & $96 \cdot 4$ & $4 \cdot 2$ & -1.79 & 0.0041 \\
\hline & Men & $96 \cdot 5$ & $7 \cdot 1$ & 0.85 & 0.4440 & $108 \cdot 3$ & 8.0 & -2.56 & 0.0423 \\
\hline \multirow[t]{2}{*}{ Meat products } & Women & $26 \cdot 3$ & $1 \cdot 8$ & 0.03 & 0.9109 & $25 \cdot 5$ & $1 \cdot 8$ & -0.33 & 0.2492 \\
\hline & Men & 34.5 & $2 \cdot 7$ & 0.30 & 0.5853 & $35 \cdot 3$ & 2.9 & -0.09 & 0.8364 \\
\hline \multirow[t]{2}{*}{ Fish } & Women & $21 \cdot 6$ & $2 \cdot 3$ & $1 \cdot 12$ & 0.0211 & $18 \cdot 7$ & $2 \cdot 5$ & 1.22 & 0.0048 \\
\hline & Men & $27 \cdot 5$ & $3 \cdot 8$ & $1 \cdot 13$ & 0.2900 & $16 \cdot 0$ & 3.9 & 0.97 & 0.1218 \\
\hline \multirow[t]{2}{*}{ Milk and dairy products } & Women & $264 \cdot 3$ & $12 \cdot 5$ & 0.67 & 0.7170 & $215 \cdot 5$ & 11.5 & $1 \cdot 31$ & 0.4055 \\
\hline & Men & $242 \cdot 6$ & 19.5 & 0.86 & 0.8210 & $203 \cdot 2$ & $20 \cdot 3$ & $2 \cdot 70$ & 0.2626 \\
\hline \multirow[t]{2}{*}{ Egg } & Women & $10 \cdot 8$ & $1 \cdot 0$ & 0.50 & 0.0207 & 9.9 & $1 \cdot 3$ & 0.27 & 0.2125 \\
\hline & Men & $14 \cdot 2$ & 1.8 & 0.16 & 0.6221 & $12 \cdot 5$ & $2 \cdot 0$ & -0.30 & 0.4266 \\
\hline \multirow[t]{2}{*}{ Vegetables } & Women & $139 \cdot 7$ & $7 \cdot 0$ & $2 \cdot 29$ & 0.0636 & $131 \cdot 7$ & $8 \cdot 1$ & 2.94 & 0.0081 \\
\hline & Men & 140.9 & $9 \cdot 8$ & $3 \cdot 38$ & 0.0360 & $112 \cdot 9$ & $9 \cdot 0$ & 3.01 & 0.0356 \\
\hline \multirow[t]{2}{*}{ Fruit and fruit products } & Women & $281 \cdot 6$ & $11 \cdot 3$ & 1.97 & 0.3223 & $246 \cdot 4$ & $12 \cdot 0$ & 1.49 & 0.4290 \\
\hline & Men & $269 \cdot 1$ & $16 \cdot 2$ & -1.89 & 0.3476 & $261 \cdot 0$ & $20 \cdot 6$ & $-4 \cdot 80$ & 0.1032 \\
\hline
\end{tabular}

$\beta$, trend results per year.

${ }^{a}$ Trend analysis in total sample shows significant difference in trend results between age groups: $P=0.0010$. 
Table 7. Energy and macronutrient intake of the GISELA subjects 1994-2002

\begin{tabular}{|c|c|c|c|c|c|c|c|c|c|}
\hline & & \multicolumn{4}{|c|}{ Subjects born 1904-1928 } & \multicolumn{4}{|c|}{ Subjects born 1929-1942 } \\
\hline & & Intercept & SE & $\beta$ & $P$ & Intercept & SE & $\beta$ & $P$ \\
\hline \multirow[t]{2}{*}{ Energy $(\mathrm{kJ} / \mathrm{d})$} & Women & $7902 \cdot 5$ & $147 \cdot 9$ & 34.71 & 0.2008 & $7649 \cdot 0$ & $157 \cdot 9$ & $2 \cdot 34$ & 0.9088 \\
\hline & Men & $9734 \cdot 7$ & $260 \cdot 7$ & -36.63 & 0.3975 & 8801.5 & $201 \cdot 6$ & $72 \cdot 02$ & 0.0011 \\
\hline \multirow[t]{2}{*}{ Energy/kg body weight (kJ/kg per d) } & Women & $120 \cdot 5$ & 2.5 & 0.70 & 0.1156 & $109 \cdot 1$ & 2.7 & -0.26 & 0.4171 \\
\hline & Men & $124 \cdot 4$ & 3.9 & -0.36 & 0.5321 & $113 \cdot 6$ & $3 \cdot 2$ & 0.33 & 0.3122 \\
\hline \multirow[t]{2}{*}{ Carbohydrates $^{a}$ (\% of energy intake) } & Women & $49 \cdot 5$ & 0.4 & -0.09 & 0.2297 & $47 \cdot 8$ & 0.6 & 0.19 & 0.0164 \\
\hline & Men & 48.4 & 0.7 & -0.34 & 0.0026 & $49 \cdot 6$ & 0.7 & -0.12 & 0.0980 \\
\hline \multirow[t]{2}{*}{ Protein $^{\mathrm{b}}$ (\% of energy intake) } & Women & $17 \cdot 6$ & 0.2 & 0.01 & 0.6786 & $17 \cdot 8$ & 0.3 & -0.00 & 0.9554 \\
\hline & Men & $16 \cdot 2$ & 0.3 & 0.31 & $<0.0001$ & $17 \cdot 1$ & 0.4 & 0.03 & 0.5722 \\
\hline \multirow[t]{2}{*}{ Fat (\% of energy intake) } & Women & $32 \cdot 7$ & 0.4 & 0.13 & 0.0782 & $33 \cdot 4$ & 0.5 & -0.09 & 0.1995 \\
\hline & Men & $32 \cdot 8$ & 0.5 & 0.11 & 0.2115 & $31 \cdot 3$ & 0.5 & 0.04 & 0.5999 \\
\hline \multirow{2}{*}{ Alcohol (\% of energy intake) } & Women & $1 \cdot 8$ & 0.2 & -0.00 & 0.9732 & 2.5 & 0.3 & -0.07 & 0.0186 \\
\hline & Men & 3.7 & 0.4 & 0.08 & 0.0226 & $4 \cdot 3$ & 0.6 & -0.09 & 0.0836 \\
\hline
\end{tabular}

$\beta$, trend results per year.

${ }^{\mathrm{a}, \mathrm{b}}$ Trend analyses in total sample show: ${ }^{\mathrm{a}}$ significant difference in trend results between age groups: $P=0.0036$; ${ }^{\mathrm{b}}$ significant difference in trend results between women and men: $P=0.0116$.

\section{Trends in food intake}

In general, the food intake of both sex and age groups of the GISELA collective stayed fairly stable over the 8 years.

Changes observed are found predominantly in the women and in the younger generations. The most obvious change is the increase of the total food intake of women in both age groups and of the younger men. This change results primarily from the higher beverage intake of the GISELA subjects.

An increased water intake is the main change observed in all subjects. Simultaneously, the consumption of coffee and black tea reduces among the women and the older men. The older men additionally decreased the intake of soft drinks and the younger women slightly increased the consumption of juices. The changes in the beverage intake recorded by the GISELA survey underline the health consciousness of the subjects, because they correspond with the recommendations, which encourage a high fluid intake, whereby the intake of water is particularly promoted. The reduction in the intake of coffee and black tea is a further positive development because of their diuretic effect (Stookey, 1999).

A comparison of the results of the GISELA study with other findings is difficult, because no study exists covering these same categories of foods or the studies available differ in assessment methods or the age groups covered. In the following, comparisons are drawn disregarding these differences in the study design. The MONICA study assessed the mean monthly food consumption frequencies and their absolute changes between 1984-5 and 1989-90 in 25-64-year-old south German subjects. The results of the MONICA study indicate an increasing trend in water intake of the men and women (Schaeffler et al. 1996). The findings are supported by statistics of the Federal Ministry of Nutrition, Agriculture and Forestry, indicating a rising trend in the national per capita consumption of mineral water (BVEL, 2003). Between the years 1985 and 2000 the same trends in the intake of water are found in German children and adolescents surveyed in the Dortmund Nutritional and Anthropometric Longitudinally Designed study (DONALD study) (Alexy et al. 2002). These corresponding findings provoke the assumption that industrial changes support the consumption of water or enable easier access to water, for example through home delivery, greater variety or the 'soda streamer', which were introduced in Germany in
1996 (Sichert-Hellert \& Kersting, 2001). The increased beverage intake of the elderly subjects is inconsistent with the findings of other studies observing a reduction of the beverage intake in the elderly provoked by a reduced sensitivity of thirst with rising age, making them a vulnerable group for dehydration (Rolls \& Phillips, 1990; Naitoh \& Burrell, 1998; Kenny \& Chiu, 2001). The GISELA subjects show that this development is not always proved.

A significant decrease in the consumption of meat is observed in the younger age groups of GISELA subjects. A decrease in the consumption of meat was also found among the MONICA subjects (Winkler et al. 2000) as well as in the children and adolescents of the DONALD study (Alexy et al. 2002) and is supported by German statistics, which indicate that the national per capita intake of meat has decreased (BVEL, 2003). The change in the younger subjects could reflect their higher involvement and thus reaction to scandals spread by mass media like the BSE crisis (Von Alvenisleben, 2002). No changes in meat intake are found in the older subjects. However, the intake of the older age groups lies below the intake of the younger subjects. These findings might indicate that meat loses importance in the higher age groups, presumably due to chewing difficulties or because the tastes of people shift to other food groups in old age.

In the 8 years the GISELA women increase the intake of fish. The opposed trend in the fish and meat intake of the younger women indicates that they substitute meat with fish. The women might eat more fish because it is positively associated with health aspects for its high contents of essential fatty acids, iodine etc. In the MONICA study an increasing trend in the consumption of fish is also observed in women as well as in men in all age groups (Schaeffler et al. 1996; Winkler et al. 2000).

Only the older GISELA men show a decreasing trend in the intake of high-carbohydrate foods, reducing the consumption of bread and bakery products as well as potatoes and potato products. They have the highest mean intake in these food groups compared to the other age and sex groups. In contrast to the other age and sex groups the older women increase their intake of potatoes and potato products, whereas the younger women reduce their intake of these, but substitute the reduction with an increase in the consumption of cereal products. The same trend was observed in the intake of flaked oats, muesli or cornflakes 
(cereal products) of women and men in the MONICA study (Schaeffler et al. 1996).

A significant increase in vegetable intake is observed in all GISELA subjects, but not in the older women, who show the same positive, but not significant tendency $(P=0.0636)$ though. The increasing trend in the consumption of vegetables is also observed in the MONICA subjects (Schaeffler et al. 1996) and is supported by German statistics, indicating an increasing national per capita consumption of vegetables (BVEL, 2003).

\section{Trends in energy and macronutrient intake}

The mean energy intake of the GISELA subjects meets the RDA in all survey years (National Research Council, 1989). A gradual decline in energy intake at old age has been observed in the SENECA study as well as in other population-based nutritional surveys (Hallfrisch et al. 1990; Sjorgens et al. 1994; MoreirasVarela et al. 1996; Wakimoto \& Block, 2001). This trend is not confirmed by the analysis of the GISELA subjects. No reduction in energy intake is found, but rather a slight increase among the younger men was recorded. It is well known that increasing age is associated with a higher prevalence of diseases as well as a higher intake of medicine (Bergmann \& Wiholm, 1981; Van den Akker et al. 1998). Both diseases as well as medications can reduce appetite resulting in a reduction of food and energy intake, which leads to a decrease in body weight (Fischer \& Johnson, 1990; Schiffman \& Zevakis, 2002). On the other hand, a stable energy intake and body weight may be an indicator for a good health status of elderly people. This assumption could also be the case for the GISELA subjects and is supported by a French study, which covered healthy elderly subjects and also observed that the energy intake of the elderly remained stable over a period of 4 years (Nicolas et al. 2000).

The contribution of fat and protein to the energy intake of the GISELA subjects is higher and the contribution of carbohydrates is lower than the RDA (National Research Council, 1989). Changes in the percentage of macronutrients of the energy intake are observed in the older men and the younger women. The older men reduce the proportion of carbohydrates and substitute them with proteins and alcohol. This decline in carbohydrates probably results from the reduction of the high-carbohydrate food intake. The young women, on the other hand, reduce the percentage of alcohol and increase the proportion of carbohydrates.

\section{Strengths and limitations of the study}

The GISELA study is the first and only longitudinal study conducted in Germany investigating time trends in dietary intake of an ageing population. Food intake of the GISELA subjects is repeatedly assessed over a long period of time (1994-2002) always using the same validated $3 \mathrm{~d}$ estimated dietary record. A special feature of the GISELA study is the high frequency of follow-ups in a relatively large sample of elderly subjects.

Some limitations of the present study have to be considered when interpreting the findings. First, the GISELA study sample is selfselected and not representative for the elderly German population. Compared to the older federal average, GISELA subjects have a higher educational level and are more health conscious. Second, the small but existent dropout rate may lead to selectivity and thus may influence the results. Therefore, the observed changes in food and energy intake cannot be generalised for the entire elderly
German population. However, observed trends in food consumption are similar to national German trends as measured by the national per capita consumption (BVEL, 2003).

\section{Conclusion}

The dietary intake of the GISELA subjects stays fairly stable over the study period. However, some changes in the consumption pattern are observed, predominantly in the women and the younger generations. Slight shifts occurred towards the consumption of foods that are more nutritious and are positively associated to health aspects, which correspond to the national trends observed in Germany. The water and vegetable intake of the GISELA subjects increased and the coffee and tea as well as the meat intake decreased. The healthier food choices and the ability to change food habits could be related to the relatively high health-awareness of the GISELA subjects compared to the federal average of equivalent age groups.

\section{References}

Alexy U, Sichert-Hellert W \& Kersting M (2002) Fifteen-year time trends in energy and macronutrient intake in German children and adolescents: results of the DONALD study. Br J Nutr 87, 595-604.

Bergmann U \& Wiholm BE (1981) Patient medication on admission to a medical clinic. Eur J Clin Pharmacol 20, 185-191.

BVEL (Bundesministerium für Verbraucherschutz, Ernährung und Landwirtschaft) (2003). Statistisches Jahrbuch über Ernährung, Landwirtschaft und Forsten. Münster-Hiltrup: Landwirtschaftsverlag GmbH.

de Almeida MD, Graca P, Afonso C, Kearney JM \& Gibney MJ (2001) Healthy eating in European elderly: concepts, barriers and benefits. $J$ Nutr Health Aging 5, 217-219.

Dehne LI, Klemm C, Henseler G \& Hermann-Kunz E (1999) The German Food Code and Nutrient Data Base (BLS II.2). Eur J Epidemiol 15, $355-359$.

Fischer J \& Johnson MA (1990) Low body weight and weight loss in the aged. J Am Diet Assoc 90, 1697-1706.

Goldberg GR, Black AE, Jebb SA, Cole TJ, Murgatroyd PR, Coward WA \& Prentice AM (1991) Critical evaluation of energy intake data using fundamental principles of energy physiology: 1. Derivation of cut-off limits to identify under-recording. Eur J Clin Nutr 45, 569-581.

Hallfrisch J, Muller D, Drinkwater T, Tobin J \& Andres R (1990) Continuing diet trends in men: the Baltimore Longitudinal Study of Aging. $J$ Gerontol 45, M186-M191.

Horwath CC (1989) Dietary intake studies in elderly people. World Rev Nutr Diet 59, 1-10.

Junge B \& Nagel M (1999) Das Rauchverhalten in Deutschland. Gesundheitswesen 61, 121-125.

Kenny WL \& Chiu P (2001) Influence of age on thirst and fluid intake. Med Sci Sports Exerc 33, 1524-1532.

Kinsella KG (1992) Changes in life expectancy 1900-1990. Am J Clin Nutr 55, 1196S-1202S.

Krems C, Lührmann PM \& Neuhäuser-Berthold M (2004) Physical activity in young and elderly subjects. J Sports Med Phys Fitness 44, $71-76$.

Littell RC, Henry PR \& Ammermann CB (1998) Statistical analysis of repeated measures data using SAS procedures. J Anim Sci 76, 1216-1231.

Lührmann P, Herbert B, Gaster C \& Neuhäuser-Berthold M (1999) Validation of a self-administered 3-day estimated dietary record for use in the elderly. Eur J Nutr 38, 235-240.

Mensink GBM (2002) Beiträge zur Gesundheitsberichterstattung des Bundes, Was essen wir heute? Ernährungsverhalten in Deutschland. Berlin: Robert-Koch-Institut.

Moreiras-Varela O, Van Staveren WA, Amorim Cruz JA, Carbajal A, de 
Henauw S, Grunenberger F \& Roskowski W (1996) Longitudinal changes in the intake of energy and macronutrients of elderly Europeans. Eur J Clin Nutr 50, 67-76.

Naitoh M \& Burrell LM (1998) Thirst in elderly subjects. J Nutr Health Aging 2, 172-177.

National Research Council (1989) Recommended Dietary Allowances. Subcommittee on the Tenth Edition of the RDAs, Food and Nutrition Board, Commission on Life Sciences, National Research Council, 10th ed. Washington, DC: National Academy Press.

Nicolas AS, Faisant C, Lanzmann-Petithory D, Tome D \& Vellas B (2000) The nutritional intake of free-living healthy French population: a four-year follow-up. J Nutr Health Aging 4, 77-80.

Rolls BJ \& Phillips PA (1990) Aging and disturbance of thirst and fluid balance. Nutr Rev 48, 137-144.

Schaeffler V, Döring A, Winkler G \& Keil U (1996) Trends in food consumption in a South German population from 1984/85 to 1989/90: results from the WHO MONICA Project Augsburg. Ann Nutr Metab 40, 129-136.

Schiffman SS \& Zevakis J (2002) Taste and smell perception in the elderly: effect of medications and disease. Adv Food Nutr Res 44, 247-346.

Schlettwein-Gsell D \& Barclay D (1996) Longitudinal changes in dietary habits and attitudes of elderly Europeans. Eur J Clin Nutr 50, 56-66.

Sichert-Hellert W \& Kersting M (2001) Fifteen year trends in water intake in German children and adolescents: results of the DONALD Study. Acta Paediatr 90, 732-737.

Sjorgens A, Österberg T \& Steen B (1994) Intake of energy, nutrients and food items in a ten-year cohort comparison and in a six-year longitudinal perspective: a population study of 70- and 76-year-old Swedish people. Age Ageing 23, 108-112.

Stookey JD (1999) The diuretic effects of alcohol and caffeine and the total water intake misclassification. Eur J Epidemiol 15, 181-188.

Van den Akker M, Buntinx F, Metsemakers JF, Roos S \& Knottnerus JA (1998) Multimorbidity in general practice: prevalence, incidence, and determinants of co-occurring chronic and recurrent diseases. $J$ Clin Epidemiol 51, 367-375.

Von Alvenisleben R (2002) Effects of BSE on consumer attitudes and behaviour. Dtsch Tierarztl Wochenschr 109, 335-337.

Wakimoto P \& Block G (2001) Dietary intake, dietary patterns, and changes with age: an epidemiological perspective. J Gerontol 56A, 65-80.

Winkler G, Döring A \& Keil U (2000) Trends in dietary sources of nutrients among middle-aged men in southern Germany. Results of the MONICA Project Augsburg: dietary surveys 1984/1985 and 1994/ 1995. Appetite 34, 37-45.

World Health Organization (1990) Diet, Nutrition and the Prevention of Chronic Diseases. Technical Report Series no. 797. Geneva: WHO.

World Health Organization (2002) Keep Fit for Life: Meeting the Nutritional Needs of Older Persons. Geneva: WHO. 